\title{
Extramedullary hematopoiesis in the adrenal: Case report and review of literature
}

\author{
John Samuel Banerji, MCh(Urology), DNB(Urology), MS, ${ }^{*}$ Ramani Manoj Kumar, MD; ; \\ Antony Devasia, FRCS(Urol), MCh(Urol), MS
}

*Department of Urology, Christian Medical College, Vellore, India; 'Department of Pathology, Christian Medical College, Vellore, India

Cite as: Can Urol Assoc J 2013;7(5-6):e436-8. http://dx.doi.org/10.5489/cuaj.1389 Published online June 12, 2013.

\section{Abstract}

Extramedullary haematopoiesis (EMH) is common in the spleen, liver and lymph nodes, or in para osseus sites. EMH in the adrenal is rare, with fewer than 10 cases reported. We report the case of a 40-year-old male who underwent laparoscopic adrenalectomy for an incidentally detected adrenal mass. The histology showed extramedullary hematopoesis. In patients with a known history of haemolytic anaemia, an enlarged adrenal gland in an asymptomatic individual could represent extramedullary haematopoesis. A confirmatory biopsy would be all that is necessary to avoid adrenalectomy.

\section{Case report}

A 40-year-old male presented with non-specific upper abdominal pain, significant weight loss and anorexia of 6 months duration.

Ultrasonographic examination elsewhere revealed an enlarged right adrenal gland. He was not known to be hypertensive, and had no other comorbid illnesses. He had pallor, but no generalized lymphadenopathy. His blood pressure was $130 / 80 \mathrm{mmHg}$. He had a splenomegaly of about $18 \mathrm{~cm}$. There was no hepatomegaly. Laboratory investigations showed a hematocrit of $30.6 \%$, a reticulocyte count of $4.3 \%$ and a platelet count of $60000 /$ cumm. The total white blood cells count was 14000 with $78 \%$ neutrophils, $16 \%$ lymphocytes, $5 \%$ monocytes and $1 \%$ basophils. Peripheral blood smear revealed anisocytosis, poikilocytosis, along with target cells and contracted red blood cells. His serum ferritin was $703.8 \mathrm{ng} / \mathrm{mL}$ (normal range: $20-320 \mathrm{ng} / \mathrm{mL}$ ). Liver function tests showed indirect hyperbilirubinemia. Serum cortisol and 24-hour urinary metanephrines were within normal limits.

A contrast enhanced computed tomography (CT) of the abdomen and pelvis revealed splenomegaly, and a homog- enous, moderately enhancing lesion measuring $8 \times 9 \mathrm{~cm}$ in the region of the right adrenal gland (Fig. 1, Fig. 2), replacing it almost completely. There was no fat within the lesion. He underwent a laparoscopic right adrenalectomy. The excised specimen was $8 \times 9 \mathrm{~cm}$, with a reddish brown surface, with no obvious fat component (Fig. 3).

Gross examination revealed a well-circumscribed brownish mass measuring $9 \mathrm{~cm}$ in maximum dimension, with a hemorrhagic, reddish brown cut surface. A rim of normal looking adrenal tissue was noted at the periphery. Histology revealed the mass to be composed of mature hemopoetic elements, with a predominance of erythroid series. A few megakaryocytes were also noted (Fig. 4).

The immunohistochemical tests done for the differential diagnosis was alpha inhibin and calretinin. The tumour was positive for alpha inhibin. A $10 \times$ magnification image is provided showing alpha inhibin positivity (Fig. 5).

An accessory spleen which can be present in this location was excluded by the absence of lymphoid follicles in multiple sections. A myelolipoma, which is another histological differential diagnosis, was ruled out by the absence of a lipomatous component. In addition, myelolipoma patients have a normal bone marrow picture. He was subsequently evaluated by a hematologist and underwent hemoglobin electrophoresis, which showed that he had homozygous delta-beta thalassemia and advised haematinics.

At follow-up 6 months after surgery, an ultrasound showed no lesion in the region of the right suprarenal area. His splenomegaly had decreased to $15 \mathrm{~cm}$, and his hemoglobin was stable at $11.2 \mathrm{gm} \%$. He continued to be on iron supplements.

\section{Discussion}

The widespread use of cross-sectional imaging modalities, such as CT scanning, has led to a multifold increase in adrenal incidentalomas. ${ }^{1}$ The adrenal glands are the seat of a wide variety of diseases. However, EMH in the adrenal is uncommon, ${ }^{2}$ with less than 10 cases reported. ${ }^{3}$ It is thought 


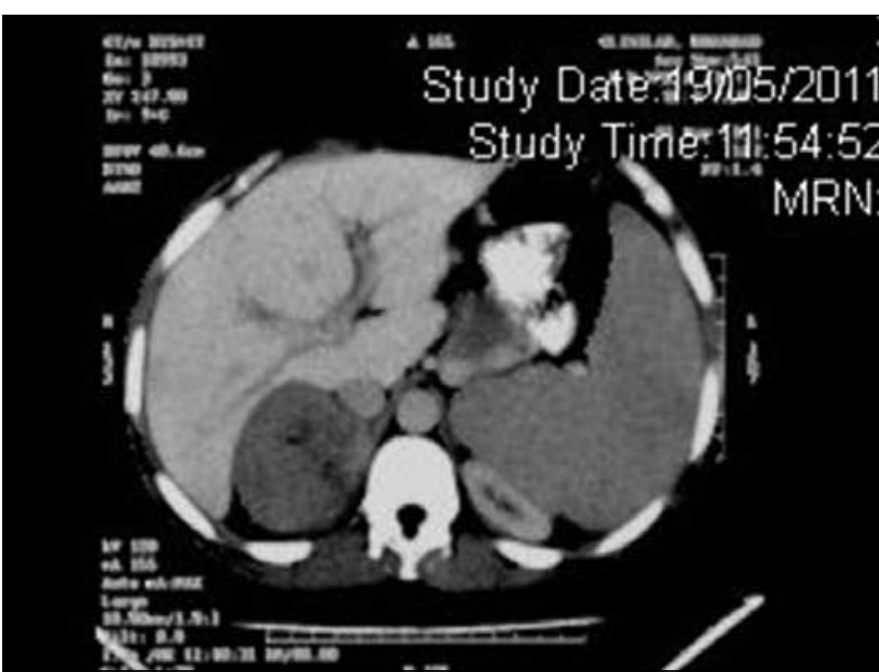

Fig. 1. Contrast enhanced computed tomography scan showing right adrenal mass.

to be a compensatory, physiological mechanism that occurs during altered medullary haematopoesis which is commonly seen in the haemoglobinopathies, leukemias, lymphomas and myelofibrosis. Recently, it has been postulated that the hematogenous spread of multipotential stem cells occurs with eventual infiltration of various tissues and organs. Patients with adrenal EMH are generally known to have beta-thalassemia major ${ }^{4,5}$ or other major haemoglobinopathies, such as hereditary spherocytosis. ${ }^{6}$

This is the first report of its occurrence in delta-beta thalassemia. There have been reports of Tc99 nanocolloid bone scintigraphy being used to detect evidence of reticuolendothelial tissue in the adrenal. Wat and colleagues have described this as a non-invasive method of detecting adrenal $\mathrm{EMH} .{ }^{7}$ The dilemma in this case was whether this was

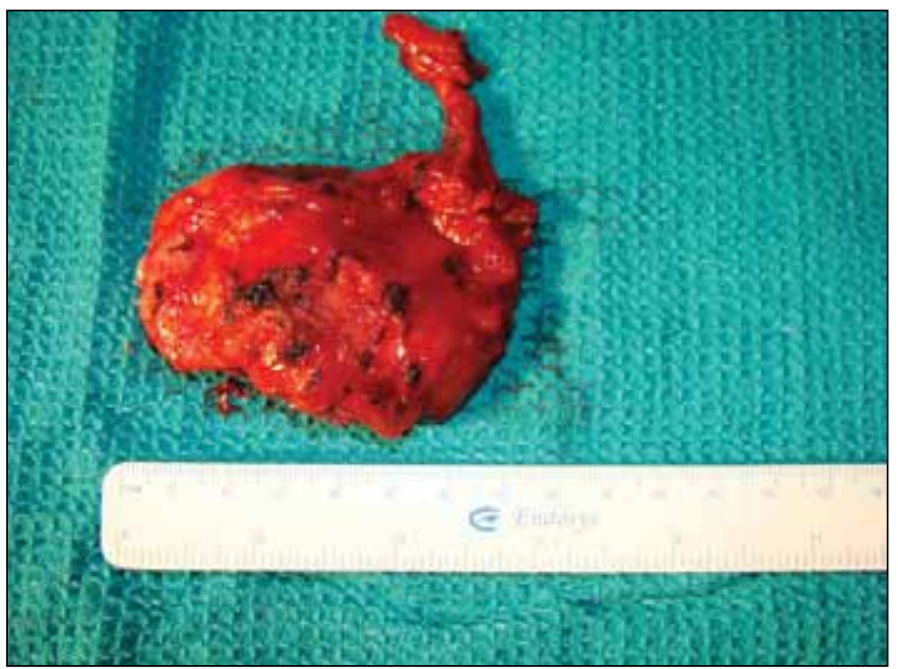

Fig. 3. Excised specimen of the right adrenal showing a reddish brown surface.

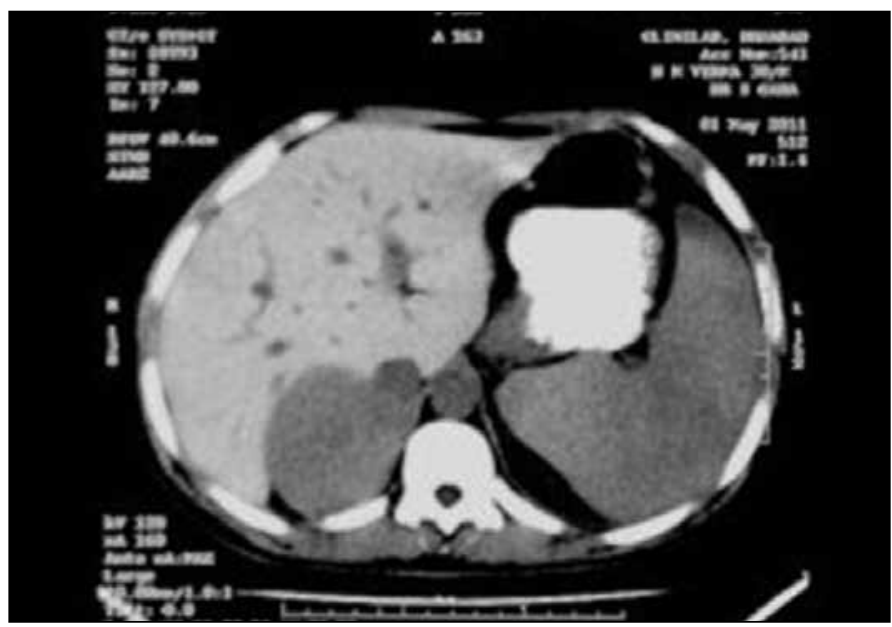

Fig. 2. Contrast enhanced computed tomography showing right adrenal mass in a lower section. The right kidney is still not seen in this section, as the adrenal mass had pushed it inferiorly.

an adrenocortical carcinoma or a non-functioning adrenal adenoma. Adrenal adenomas normally do not grow larger than $3 \mathrm{~cm}$. Moreover, the Hounsfield densities in adrenal adenomas are less than 0 in an unenhanced CT. ${ }^{8}$ By size criteria alone, the likelihood of this mass being an adrenocortical carcinoma was high. Therefore, an adrenalectomy was performed in this patient. With the history of weight loss, a malignant process was thought of initially. However, adrenocortical carcinomas are heterogeneously enhancing and highly vascular..$^{8,9}$ The anemia and splenomegaly could have been pointers towards the diagnosis of an underlying hematological disorder.

The urologist and the endocrine surgeon should be aware of this entity, and an image guided biopsy of the adrenal gland in most instances is likely to give the diagnosis.

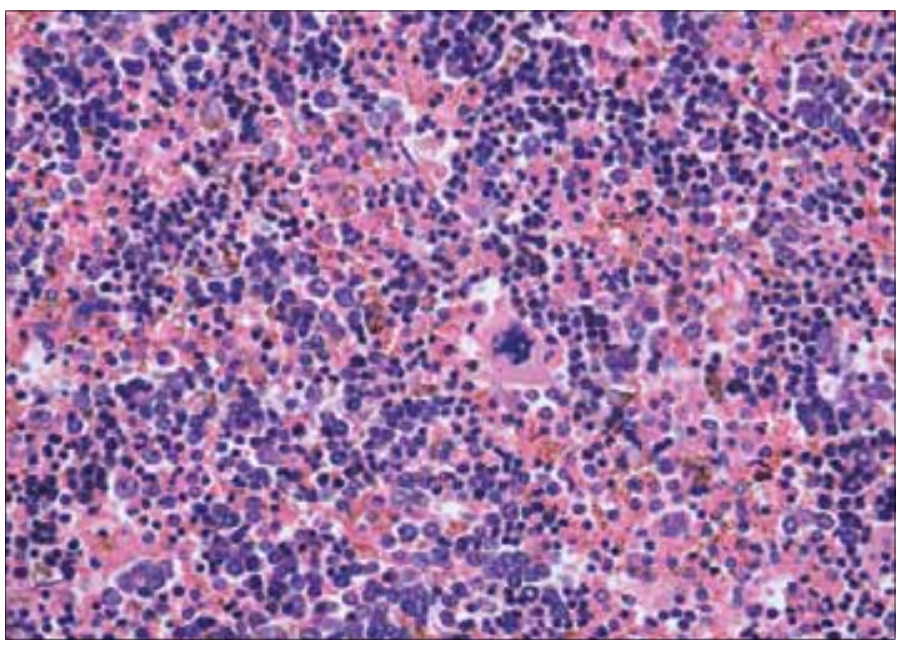

Fig. 4. Hematoxylin and eosin stain showing a large megakaryocyte, seen in the centre. 
Banerji et al.

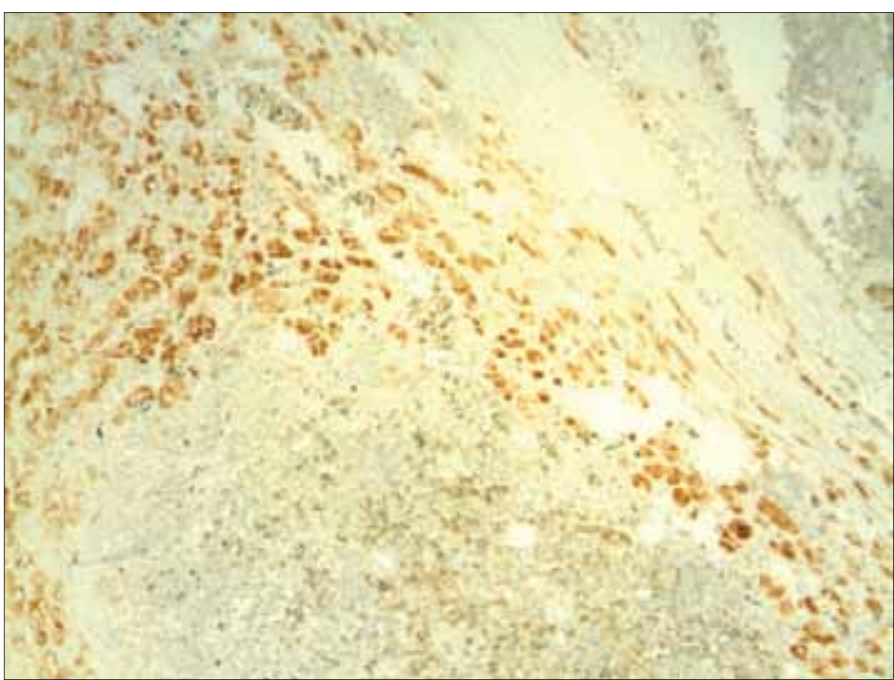

Fig. 5. A $10 \times$ magnification showing alpha inhibin positivity.

\section{Conclusion}

In the setting of a hematological disorder, a biopsy is indicated in the management of an adrenal incidentaloma. If it reveals extramedullary haematopoesis, excision can be avoided.

Competing interests: None declared.
This paper has been peer-reviewed.

\section{References}

1. Young WF Jr. The incidentally discovered adrenal mass. N Engl J Med 2007;356:601-10. http://dx.doi.org/10.1056/NEJMcp065470

2. Georgiades $C S$, Neyman $E G$, Francis IR, et al. Typical and atypical presentations of extramedullary hematopoiesis. AJR Am J Roentgenol 2002;179:1239-43. http://dx.doi.org/10.2214/ojr.179.5.1791239

3. Porcaro $A B$, Novella $G$, Antoniolli $S Z$, et al. Adrenal extramedullary hematopoiesis: report on a pediatric case and update of the literature. Int Urol Nephrol 2001;33:601-3. http://dx.doi.org/10.1023/A:1020578501167

4. Gamberini MR, Prandini N, Chiodi E, et al. Adrenal incidentaloma in thalassemia: a case report and literature review. Pediatr Endocrinol Rev 2011;8(Suppl 2):324-30.

5. Tunaci M, Tunaci A, Engin G, et al. Imaging features of thalassemia. Eur Radiol 1999;9:1804-9. http://dx.doi.org/10.1007/s003300050926

6. Calhoun SK, Murphy RC, Shariati N, et al. Extramedullary hematopoiesis in a child with hereditary spherocytosis: an uncommon cause of an adrenal mass. Pediatr Radiol 2001;31:879-81. http://dx.doi.org/10.1007/s002470100011

7. Wat NM, Tse KK, Chan FL, et al. Adrenal extramedullary haemopoiesis: diagnosis by a non-invasive method. Br J Haematol 1998;100:725-7. http://dx.doi.org/10.1046/i.1365-2141.1998.00619.x

8. King BF, Kopecky KK, Baker MK, et al. Extramedullary hematopoiesis in the adrenal glands: CT characteristics. J Comput Assist Tomogr 1987;11:342-3. http://dx.doi.org/10.1097/00004728-198703000-00030

9. Lau HY, Lui DC, Ma JK, et al. Sonographic features of adrenal extramedullary hematopoiesis. J Ultrasound Med 2011;30:706-13.

Correspondence: Dr. John Samuel Banerii, Associate Professor, Department of Urology, Christian Medical College, Vellore, India; johnsbanerji@cmcvellore.ac.in 